\title{
SPARKLE (Subtypes of Ischaemic Stroke Classification System), Incorporating Measurement of Carotid Plaque Burden: A New Validated Tool for the Classification of Ischemic Stroke Subtypes
}

\author{
Chrysi Bogiatzi ${ }^{a}$ b Thapat Wannarong ${ }^{a}$ A. Ian McLeod ${ }^{c}$ Marnin Heisel ${ }^{b, d}$ \\ Daniel Hackam ${ }^{a, b, e, f}$ J. David Spence ${ }^{a, e, f}$ \\ a Stroke Prevention and Atherosclerosis Research Centre, Robarts Research Institute, ${ }^{b}$ Department of Epidemiology \\ and Biostatistics, ${ }^{C}$ Department of Statistical and Actuarial Sciences, ${ }^{d}$ Department of Psychiatry, ${ }^{e}$ Division of Clinical \\ Pharmacology, ${ }^{\mathrm{f}}$ Division of Neurology, Western University, London, Ont., Canada
}

\section{Key Words}

Ischemic stroke - Etiological classification .

Total plaque area $\cdot$ Validity $\cdot$ Reliability

\begin{abstract}
Background: Previous classification systems of acute ischemic stroke (Causative Classification System, CCS, of acute ischemic stroke, Trial of Org 10172 in Acute Stroke Treatment, TOAST) established the diagnosis of large artery disease (LAD) based on the presence or absence of carotid stenosis. However, carotid plaque burden is a stronger predictor of cardiovascular risk than stenosis. Our objective was to update definitions of ischemic stroke subtypes to improve the detection of $L A D$ and to assess the validity and reliability of a new classification system: SPARKLE (Subtypes of Ischaemic Stroke Classification System). Methods: In a retrospective review of clinical research data, we compared three stroke subtype classifications: CCS, TOAST and SPARKLE. We analyzed a random sample of 275 patients presenting with minor stroke or transient ischemic attack (TIA) in an Urgent TIA Clinic in London, Ont., Canada, between 2002 and 2012. Results: There was substantial overall agreement between SPARKLE and CCS $(K=0.75)$, with significant differences in the rate of detection of $L A D$, cardioembolic and undeter-
\end{abstract}

\section{KARGER}

(c) 2014 S. Karger AG, Base

$0251-5350 / 14 / 0424-0243 \$ 39.50 / 0$

E-Mail karger@karger.com

www.karger.com/ned mined causes of stroke or TIA. The inter-rater reliability of SPARKLE was substantial $(\mathrm{K}=0.76)$ and the intra-rater reliability was excellent $(K=0.91)$. Conclusion: SPARKLE is a valid and reliable classification system, providing advantages compared to CCS and TOAST. The incorporation of plaque burden into the classification of LAD increases the proportion of cases attributable to $L A D$ and reduces the proportion classified as being of 'undetermined' etiology.

ㄷ 2014 S. Karger AG, Basel

\section{Introduction}

Classification systems for stroke are dynamic approaches that improve over time with better understanding of the pathogenesis of cerebrovascular disease and with improvements in investigation. In clinical practice, a simple and informative classification system enables early initiation of appropriate treatment to reduce recurrent stroke [1].

In 1978, the Harvard Cooperative Stroke Registry classification was introduced, at a time when only $3 \%$ of pa-

Dr. T. Wannarong is now at the Department of Internal Medicine, Siriraj Hospital, Mahidol University, Bangkok, Thailand.
Dr. J. David Spence

Stroke Prevention and Atherosclerosis Research Centre

Robarts Research Institute

1400 Western Road, London, ON N6G2V2 (Canada)

E-Mail dspence@ robarts.ca 


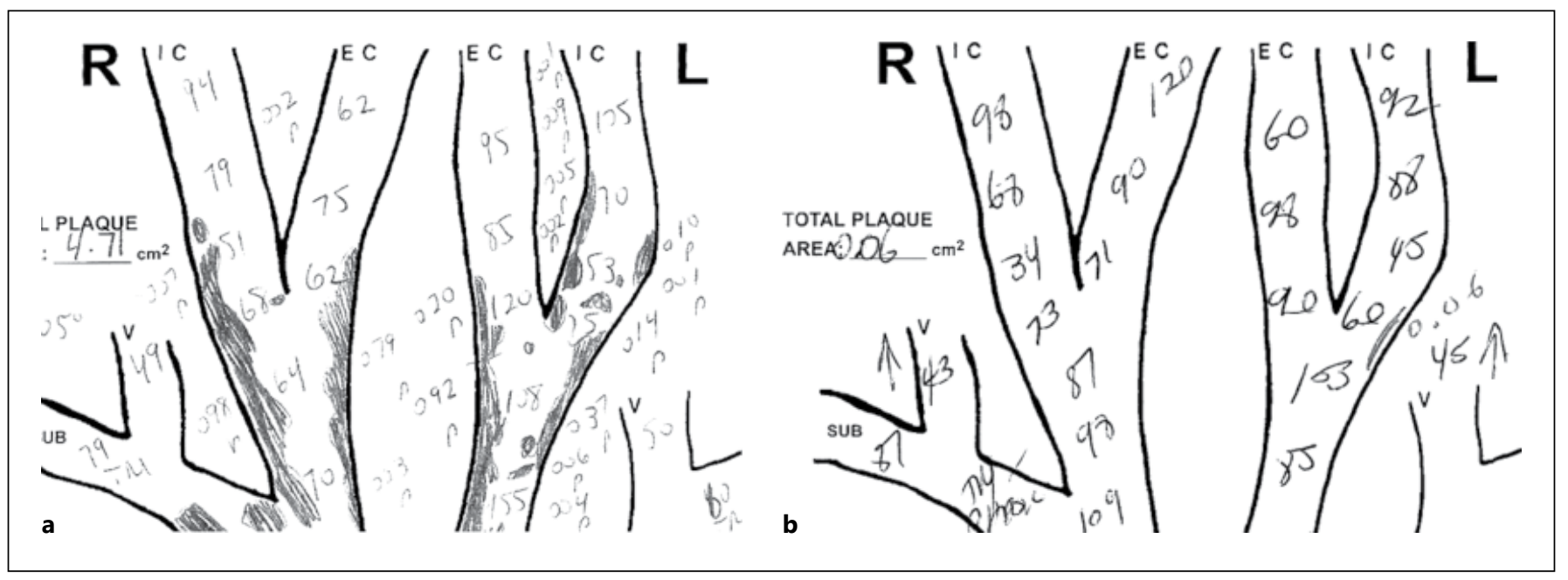

Fig. 1. Measurement of plaque burden adds to the diagnosis of stroke subtype. a Although it may be intuitive that patients without stenosis do not have much plaque, in fact many patients without carotid stenosis of $50 \%$ or more have LAD with a high TPA. This is thought to be due to compensatory enlargement of the artery, as described by Glagov et al. [40]. This composite drawing of carotid plaques from the ultrasound report of a normotensive 79-year-old woman with atherosclerotic stroke shows a very high plaque burden $\left(\mathrm{TPA}=4.71 \mathrm{~cm}^{2}\right.$, approximately 9 times normal for age and

tients were assessed with CT $[2,3]$. This classification was replaced in 1988 by the Stroke Data Bank classification system, by which point $97 \%$ of patients received CT, and the pathogenesis of ischemic stroke subtypes was better understood [3, 4]. MRI and echocardiography were then added to the assessment procedures. With these enhanced imaging modalities, the Trial of Org 10172 in Acute Stroke Treatment (TOAST) provided a more comprehensive etiological grouping of ischemic stroke subtypes with similar management [5]. However, the TOAST system classified cases with more than one cause of stroke as being of 'undetermined' etiology; hence, cases with welldefined yet multicausal etiologies were pooled under the broad undetermined category. In 2005, the Causative Classification System (CCS) of acute ischemic stroke was developed, allowing for classification of patients with multiple causes of stroke according to the 'most probable' cause of the presenting cerebrovascular event [6].

All these classification systems have been developed using data from patients with ischemic stroke. However, TOAST has been used by many studies with patients presenting with transient ischemic attack (TIA) [7-9]. In addition, a study by Amort et al. [10] showed that TOAST and CCS provide a similar distribution of ischemic stroke subtypes in patients with TIA to patients with ischemic stroke. sex); the peak velocities (numbers written into the lumen) show that there was no internal carotid stenosis. b In contrast, this composite drawing shows almost no plaque $\left(\mathrm{TPA}=0.06 \mathrm{~cm}^{2}\right)$ in a normotensive 72-year-old man with no carotid stenosis and cryptogenic stroke (normal TPA for age and sex would be more than 10 times higher $-0.8 \mathrm{~cm}^{2}$ ). The absence or near absence of plaque in a normotensive patient without diabetes raises the suspicion of a cardioembolic source, dissection or other unusual cause of stroke.

In the TOAST and CCS classification systems, large artery disease (LAD) is limited to patients with carotid stenosis, thus excluding patients who may have severe plaque burden $[2,4-6]$. Figure 1 shows that this approach is problematic. Atherosclerosis burden, measured as total plaque area (TPA), strongly predicts stroke, death or myocardial infarction [11]. Indeed, TPA is a stronger predictor of stroke, myocardial infarction or death than carotid stenosis [12]. Moreover, after risk assessment based on risk factors, the addition of TPA increases the area under the curve for the prediction of cardiovascular events [13]. Thus, a classification system of ischemic stroke should include a measurement of plaque burden in the definition of LAD. Therefore, our main objective in this study was to revisit the definition of ischemic stroke subtypes, including ultrasound assessment of the burden of atherosclerosis measured by TPA [14-16]. We hypothesized that SPARKLE (Subtypes of Ischaemic Stroke Classification System) would classify correctly patients with LAD who are missed by TOAST and CCS.

Based on the results of our 2002 study, in our source population (among whom only 19\% had experienced a prior stroke) TPA $\geq 1.19 \mathrm{~cm}^{2}$ was associated with a $19.5 \%$ 5 -year risk of stroke, death or myocardial infarction, after 
adjustment for coronary risk factors [11]. Consequently, we included in our definition of LAD a high risk TPA $\geq 1.19 \mathrm{~cm}^{2}$ in the top quartile of that study population, acknowledging that this value might differ in populations with different distributions of stroke risk factors and demographic characteristics.

We additionally sought to assess the validity of this new classification system, SPARKLE, compared to the former classifications (CCS and TOAST). We hypothesized that the use of the SPARKLE system would lead to fewer patients being assigned to the undetermined category compared to CCS and TOAST. Our third objective was to assess the reliability of SPARKLE. We expected that SPARKLE would emerge as a reproducible classification system demonstrating consistent results both between and within raters.

\section{Patients and Methods}

\section{Sample}

We conducted a retrospective analysis of data collected from patients referred to the Urgent TIA Clinic at the University Hospital in London, Ont., between 2002 and 2012. Eligible patients were included if they experienced their first lifetime minor stroke or TIA. Patients were excluded if they had a documented history of stroke/TIA before 2002 or if their final diagnosis was a stroke mimic such as a seizure or brain tumor. Data used in this study are part of a retrospective study assessing secular trends in ischemic stroke subtypes in the Thames Valley area of Ontario that was approved by the Research Ethics Board of the Western University of Health Sciences.

The total study sample consisted of 275 patients, comprising random samples of 25 patients per year seen between 2002 and 2012. Ischemic stroke subtypes for all cases were classified by a physician (C.B.) based on information collected from patient medical charts, according to the criteria presented in table 1 .

\section{The SPARKLE System}

SPARKLE is a novel classification system that was developed as an adaptation of the CCS algorithm [6], by including TPA measurements [11] in the definition of LAD.

The SPARKLE system classifies patients with multiple etiologies of cerebrovascular disease and more than one 'evident' cause of stroke/TIA based on the most 'probable' stroke/TIA subtype. Cases with more than one 'possible' cause of stroke/TIA are classified according to the most possible stroke/TIA subtype. The identification of clinical outcomes and the assignment of cases in the most probable or most possible cause of stroke/TIA rely on information from the patients' history showing a close temporal relationship between the onset of a stroke-related medical condition to the onset of stroke/TIA symptoms and a mechanism of disease explaining the presenting stroke/TIA. 'Incomplete investigation' is assigned to patients who have an indication for additional investigation and who do not attend their appointment or for whom additional tests are not performed.

SPARKLE: A New Tool for the Classification of Ischemic Stroke Subtypes
SPARKLE consists of five ischemic stroke/TIA subtypes: LAD, cardioembolic, small vessel disease (SVD), other rare or unusual etiology, and undetermined etiology. Diagnostic criteria and definition of ischemic stroke/TIA subtypes are provided in table 1 . High-risk cardiac sources of embolism, classified as evident cardioembolic, and low-risk cardiac diseases, classified as possible cardioembolic causes of stroke/TIA, are provided in online supplementary table 2 (for all online suppl. material, see www.karger. com/doi/10.1159/000362417).

\section{Procedures}

A stroke expert (J.D.S.) examined all patients at the clinic, at the time of the referral, between 2002 and 2012. J.D.S. performed basic standardized clinical assessment (medical history, physical examination, examination of brain and vascular imaging) and ordered additional investigation where needed (e.g. cardiac investigations were ordered when there was evidence or suspicion of cardiac sources of embolism). Subsequently, a final clinical diagnosis of the ischemic stroke subtype was confirmed or altered after receiving results from all additional laboratory diagnostic tests.

During the second half of 2012, the first author (C.B.) collected all eligible cases and classified them according to SPARKLE, CCS and TOAST at baseline, and also recorded recurrent stroke/TIA events based on SPARKLE and CCS. At the same time, C.B. determined SPARKLE classification at the 1-year follow-up after the first stroke/TIA (for patients who had at least 1 year of follow-up) to validate the classification as more information was accumulated (table 1). Finally, C.B. repeated the classification of all baseline stroke/TIA based on SPARKLE, with a period of more than 6 months between the first and second assessment, in order to evaluate consistency in rating clinical data using the SPARKLE classification system at different times of assessment.

A second physician (T.W.) assessed independently the same 275 cases at baseline using SPARKLE to determine the inter-rater reliability between C.B. and T.W.

To assess the relationship between carotid stenosis and TPA, we queried our current database of 7,217 patients with measurement of both TPA and carotid stenosis by Doppler peak velocity.

\section{Statistical Analysis}

Results from the assignment of cases based on SPARKLE, CCS and TOAST at baseline were analyzed using McNemar's test for the comparison of discordant dependent cases [17]. Alpha was set at 0.05 . Cohen's kappa was used to assess agreement.

Agreement was assessed between SPARKLE and CCS at baseline and between SPARKLE and TOAST at baseline. Agreement was also measured between baseline and 1-year follow-up adjudication of cases as well as between baseline and recurrent events based on SPARKLE. Also, agreement was assessed between baseline and recurrent events based on CCS. Finally, Cohen's kappa was used to measure the agreement between the two raters and derive the intra- and the inter-rater reliability of SPARKLE [18].

The strength of the agreement was interpreted based on the criteria of Landis and Koch [19] as poor $(\kappa=0.00)$, slight $(\kappa=$ $0.00-0.20)$, fair $(\kappa=0.21-0.40)$, moderate $(\kappa=0.41-0.60)$, substantial $(\kappa=0.61-0.80)$ and excellent $(\kappa>0.80)$ agreement. Analyses were performed using $\mathrm{R}$ version 2.15.2 [20]. 
Table 1. The SPARKLE System

\begin{tabular}{|c|c|c|}
\hline Subtypes & Definitions & \\
\hline \multirow[t]{5}{*}{ LAD } & $\begin{array}{l}\text { Clinical } \\
\text { criteria }\end{array}$ & $\begin{array}{l}\text { (1) Fluctuating symptoms with varying periods of gradual worsening and improvement, involving } \\
\text { cerebral, cortical, cerebellar or brain stem dysfunction [34] } \\
\text { (2) Amaurosis fugax can be present } \\
\text { (3) Symptoms suggesting subclavian steal syndrome [35] } \\
\text { (4) Cardiac sources of embolism must be excluded }\end{array}$ \\
\hline & $\begin{array}{l}\text { Laboratory } \\
\text { criteria }\end{array}$ & $\begin{array}{l}\text { (1) CT or MRI indicating infarction } \geq 2 \mathrm{~cm} \text { or normal imaging [6] } \\
\text { (2) Carotid and/or transcranial Doppler ultrasound } \\
\text { (3) Angiography, in the presence of significant carotid or intracranial stenosis }\end{array}$ \\
\hline & $\begin{array}{l}\text { Evident } \\
\text { etiology }\end{array}$ & $\begin{array}{l}\text { (1) Ipsilateral internal carotid or intracranial stenosis } \geq 50 \% \text {, or } \\
\text { (2) TPA } \geq 1.19 \mathrm{~cm}^{2} \text { with absence of evidence of acute infarction in vascular territories other than the } \\
\text { symptomatic vascular territory } \\
\text { (3) Microemboli detection on continuous transcranial Doppler monitoring }[36,37] \\
\text { (4) Subclavian steal syndrome on carotid Doppler ultrasound [35] }\end{array}$ \\
\hline & $\begin{array}{l}\text { Probable } \\
\text { etiology }\end{array}$ & $\begin{array}{l}\text { (1) Presence of another evident cause of stroke, other than LAD } \\
\text { (2) Presence of significant carotid and intracranial atherosclerosis ipsilateral to the vascular territory } \\
\text { generating stroke symptoms, with confirmation of stroke signs through the neurological assessment } \\
\text { (3) Past history of TIA or amaurosis fugax ipsilateral to the carotid or intracranial vascular territory } \\
\text { having significant stenosis }\end{array}$ \\
\hline & $\begin{array}{l}\text { Possible } \\
\text { etiology }\end{array}$ & $\begin{array}{l}\text { (1) Presence of carotid atherosclerosis causing stenosis }<50 \% \text {, or } \\
\text { (2) Presence of } 0.12 \mathrm{~cm}^{2} \leq \mathrm{TPA}<1.19 \mathrm{~cm}^{2} \text { indicating lower-risk carotid atherosclerotic lesions } \\
\text { (3) Presence of any possible cause of stroke/TIA not related with symptom onset or presenting } \\
\text { stroke/TIA }\end{array}$ \\
\hline \multirow[t]{5}{*}{ Cardioembolic } & $\begin{array}{l}\text { Clinical } \\
\text { criteria }\end{array}$ & $\begin{array}{l}\text { (1) Acutely developed cerebral or cortical symptoms of increased severity at the onset of the event } \\
\text { with rapid clinical improvement [38] } \\
\text { (2) Symptoms and signs indicate involvement of multiple vascular territories }\end{array}$ \\
\hline & $\begin{array}{l}\text { Laboratory } \\
\text { criteria }\end{array}$ & $\begin{array}{l}\text { (1) CT or MRI indicating cerebral or cortical infarction } \\
\text { (2) Echocardiogram investigating high- and/or low-risk cardiac sources of embolism } \\
\text { (3) Transcranial Doppler Bubble Study } \\
\text { (4) Carotid ultrasound excludes presence of LAD }\end{array}$ \\
\hline & $\begin{array}{l}\text { Evident } \\
\text { etiology }\end{array}$ & $\begin{array}{l}\text { (1) Multiple territory acute infarcts in brain imaging or symptoms and signs suggesting multiple } \\
\text { territory involvement } \\
\text { (2) Presence of high-risk cardiac sources of embolism }\end{array}$ \\
\hline & $\begin{array}{l}\text { Probable } \\
\text { etiology }\end{array}$ & $\begin{array}{l}\text { (1) Presence of another evident cause of stroke other than a high-risk cardiac source of embolism } \\
\text { (2) Presence of acute multiple territory infarctions strongly related to cardiac sources of embolism }\end{array}$ \\
\hline & $\begin{array}{l}\text { Possible } \\
\text { etiology }\end{array}$ & $\begin{array}{l}\text { (1) Multiple territory acute infarcts in brain imaging or symptoms and signs suggesting multiple } \\
\text { territory involvement } \\
\text { (2) Presence of low-risk cardiac sources of embolism } \\
\text { (3) Presence of any other possible cause of stroke of stroke/TIA with a mechanism of disease not } \\
\text { related with multiple territory acute stroke/TIA }\end{array}$ \\
\hline \multirow[t]{3}{*}{ SVD } & $\begin{array}{l}\text { Clinical } \\
\text { criteria }\end{array}$ & $\begin{array}{l}\text { (1) Presence of } 1 \text { of the } 5 \text { lacunar syndromes: pure motor hemiparesis, pure sensory stroke, ataxic } \\
\text { hemiparesis, sensorimotor stroke, dysarthria-clumsy hand syndrome [39] } \\
\text { (2) Absence of cortical or cerebral dysfunction }\end{array}$ \\
\hline & $\begin{array}{l}\text { Laboratory } \\
\text { criteria }\end{array}$ & $\begin{array}{l}\text { (1) CT or MRI indicating deep brain infarction } \leq 2 \mathrm{~cm} \text { without focal stenosis or other vascular } \\
\text { pathology (e.g. dissection, vasculitis) [6] } \\
\text { (2) Carotid and transcranial ultrasound excludes LAD } \\
\text { (3) Echocardiography excludes cardiac source of embolism }\end{array}$ \\
\hline & $\begin{array}{l}\text { Evident } \\
\text { etiology }\end{array}$ & $\begin{array}{l}\text { (1) Medical history and physical examination suggesting presence of a lacunar syndrome } \\
\text { (2) CT or MRI confirms deep brain infarction of a diameter } \leq 2 \mathrm{~cm}[6]\end{array}$ \\
\hline
\end{tabular}


Table 1. (continued)

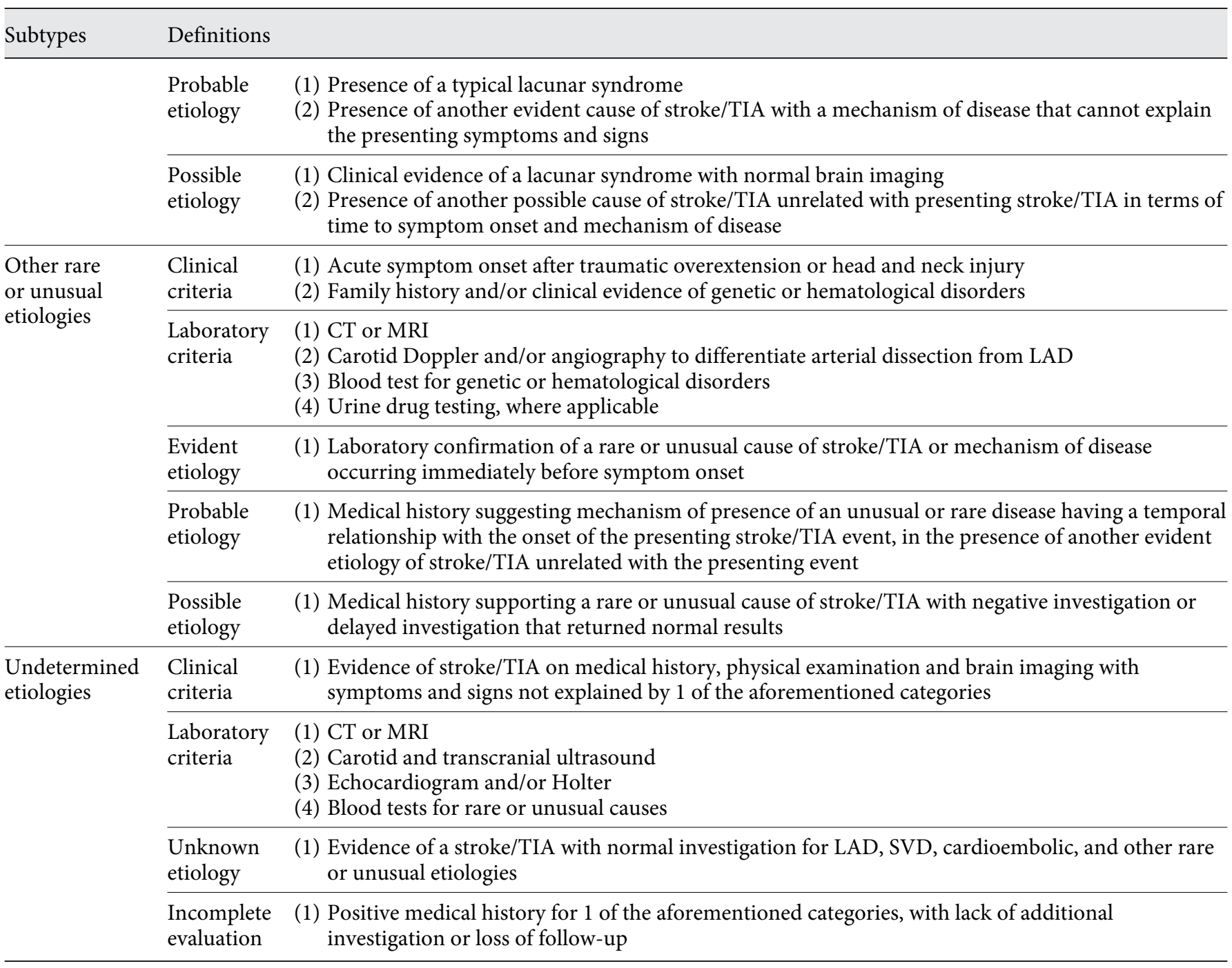

\section{Results}

Among the 7,217 cases in the Stroke Prevention and Atherosclerosis Research Centre (SPARC) database, 1,535 (21\%) had internal carotid stenosis $\geq 50 \%$ on either side and $2,391(33 \%)$ had a TPA $\geq 1.19 \mathrm{~cm}^{2}$. Of the cases with TPA $\geq 1.19 \mathrm{~cm}^{2}, 1,535(21 \%)$ had a stenosis of $50 \%$ or greater of either internal carotid artery. Among the 1,535 cases with stenosis, 1,170 (76\%) had TPA $\geq 1.19 \mathrm{~cm}^{2}$. Online supplementary figure 1 shows the distribution of carotid stenosis by TPA; the Pearson correlation coefficient between the percent stenosis of the internal carotid artery with the more severe stenosis and TPA was $0.55(\mathrm{p}=0.0001)$.

Baseline characteristics of the 275 patients are provided in online supplementary table 1 . At baseline, the agree-

SPARKLE: A New Tool for the

Classification of Ischemic Stroke Subtypes ment between SPARKLE and CCS was substantial $(\kappa=$ 0.75 ) and the agreement between SPARKLE and TOAST was fair $(\kappa=0.38)$. There was a significant difference between SPARKLE and both CCS and TOAST in LAD, cardioembolic and undetermined cause of stroke/TIA (table 2). No significant differences were found between SPARKLE and CCS or between SPARKLE and TOAST in patients with SVD and other rare or unusual cause of stroke/TIA (table 2).

Figure 2 presents Venn diagrams for the five ischemic stroke/TIA subtypes comparing SPARKLE, CCS and TOAST at baseline. The three classification systems exhibited nonsignificant differences concerning SVD with only 3 cases falling under the undetermined etiology in TOAST in the presence of multiple causes of 


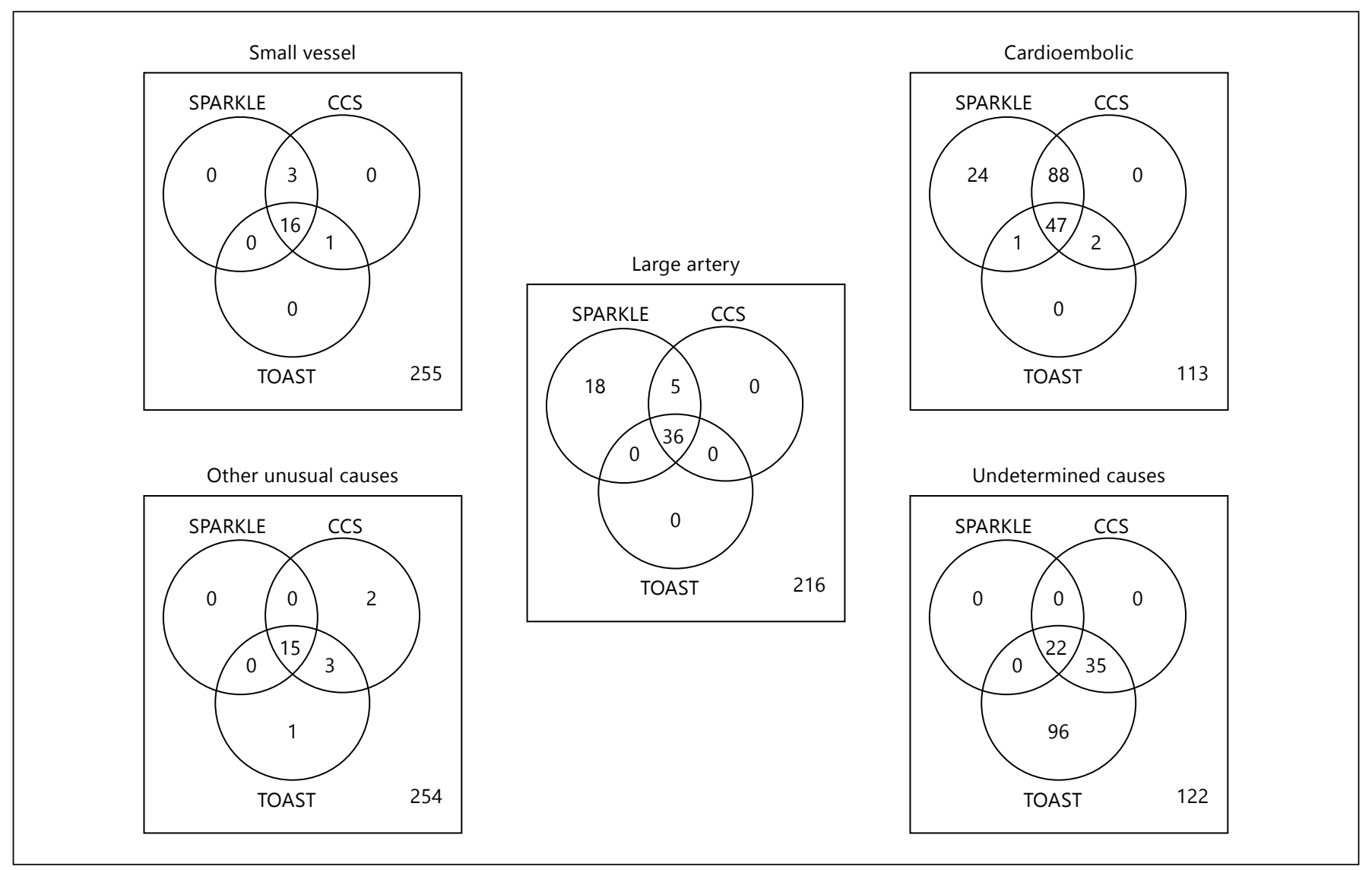

Fig. 2. Venn diagrams showing the agreement/discordance among the 3 classification systems. SPARKLE identified significantly more patients with LAD and cardioembolic stroke/TIA compared to CCS and TOAST. By classifying fewer patients under the unde- termined category, SPARKLE offers the opportunity for more appropriate treatment to reduce the risk of recurrent stroke. The bottom right number in the Venn diagrams denotes the number of cases not classified under each ischemic stroke subtype.

Table 2. Comparison of SPARKLE, CCS and TOAST

\begin{tabular}{|c|c|c|c|c|c|c|c|c|}
\hline & \multicolumn{2}{|c|}{ SPARKLE } & \multicolumn{2}{|c|}{ CCS } & \multicolumn{2}{|c|}{ TOAST } & \multirow{2}{*}{$\begin{array}{l}\text { SPARKLE } \\
\text { vs. CCS } \\
\text { p value }\end{array}$} & \multirow{2}{*}{$\begin{array}{l}\text { SPARKLE } \\
\text { vs. TOAST } \\
\text { p value }\end{array}$} \\
\hline & $\mathrm{n}$ & $\%$ & $\mathrm{n}$ & $\%$ & $\mathrm{n}$ & $\%$ & & \\
\hline LAD & 59 & 22 & 40 & 15 & 36 & 13 & & \\
\hline Cardioembolic & 160 & 58 & 138 & 50 & 50 & 18 & $<0.001$ & $<0.001$ \\
\hline SVD & 19 & 7 & 20 & 7 & 17 & 6 & 1 & 0.63 \\
\hline Other & 15 & 6 & 20 & 7 & 19 & 7 & 0.13 & 0.06 \\
\hline Undetermined & 22 & 8 & 57 & 21 & 153 & 56 & $<0.001$ & $<0.001$ \\
\hline Total & 275 & & 275 & & 275 & & & \\
\hline
\end{tabular}

stroke/TIA. There were 18 patients with LAD in SPARKLE who were classified as undetermined in CCS and TOAST in the absence of TPA criterion. Also, 131 cases with either multiple causes of stroke/TIA or high TPA without carotid stenosis and otherwise LAD in
SPARKLE were classified under the undetermined category in TOAST.

Additional analysis showed an excellent agreement in SPARKLE between the first adjudication of stroke/TIA and the 1-year follow-up adjudication $(\kappa=0.95)$ and sub- 
stantial agreement between baseline and recurrent events $(\kappa=0.71)$. Similarly, substantial agreement was shown between baseline and recurrent events based on the CCS classification $(\kappa=0.68)$. In patients who had recurrent events, SPARKLE classified fewer cases in the undetermined category compared to CCS.

Finally, the assessment of reliability of SPARKLE showed an excellent rater consistency over time $(\kappa=0.91)$ and substantial inter-rater agreement $(\kappa=0.76)$.

\section{Discussion}

We propose that SPARKLE may be useful in informing the medical management of patients with acute stroke/TIA using minimal diagnostic tests and accommodating the latest in diagnostic tools [1]. It introduces a diagnostic tool for atherosclerosis (TPA), which is easy to measure with a regular ultrasound machine and without specific software requirements [11].

In their recently published population-based study, Palm et al. [21] used CCS with the addition of a criterion for 'probable atherosclerosis', suggesting the need for more precise criteria for LAD diagnosis. In SPARKLE, we quantified plaque burden based on stratified high (TPA $\geq 1.19 \mathrm{~cm}^{2}$ ) and low (TPA $<0.12 \mathrm{~cm}^{2}$ ) stroke risk. Using a $\mathrm{TPA} \geq 1.19 \mathrm{~cm}^{2}$ to identify LAD resulted in the detection of $33 \%$ of cases with LAD compared to only $21 \%$ based on stenosis. Limiting the diagnosis to cases with stenosis underestimates the presence of high-risk LAD and potentially limits more intensive medical treatment that can significantly reduce the risk of recurrent stroke [14].

SPARKLE classified fewer cases into an undetermined category, thereby potentially enhancing preventive therapy.

Adams et al. [5] discussed the similarity of risk factors for SVD and LAD. The differential diagnosis of hypertensive, atherosclerotic or even cardioembolic origin of small subcortical infarcts is challenging. A genetic analysis in patients with SVD showed that $34 \%$ of cases had a genetic profile similar to cardioembolic stroke, $13 \%$ had a genetic profile of LAD and $47 \%$ were predicted to have SVD [22]. However, based on current knowledge, we decided to retain the description of the classical clinical lacunar syndromes referred to as SVD as previously described, acknowledging that this subtype of stroke/TIA might change in the future when new evidence emerges.

Although SPARKLE did not provide a better description of SVD and of other rare or unusual causes of stroke/ TIA than CCS or TOAST, it introduced more informa-

SPARKLE: A New Tool for the

Classification of Ischemic Stroke Subtypes tion for the classification of cases into LAD and cardioembolic stroke/TIA subtypes. Indeed, with the inclusion of the TPA criterion, SPARKLE identified 18 more cases with LAD that would have been missed in CCS and classified 20 more cases with possible cardioembolic stroke/ TIA than did CCS. These results verify the content validity of SPARKLE by including all dimensions of ischemic stroke/TIA subtypes [23]. Moreover, the substantial agreement between SPARKLE and CCS supports the construct validity of SPARKLE [23]. Finally, SPARKLE showed an excellent agreement between baseline and 1-year follow-up adjudication of stroke/TIA that indicates the validity of diagnosing cases as more information is accumulated.

The inter-rater reliability of SPARKLE $(\kappa=0.76)$ was not substantially different from that for CCS $(\kappa=0.8)$ [24]. The greatest disagreement between the two raters occurred when information from the medical history was overlooked.

There was no significant difference in follow-up events between SPARKLE and CCS other than CCS classifying more cases under the undetermined category.

First and foremost, an unavoidable limitation of all stroke classification systems is the inability to compare the results with a gold standard, which ideally is the pathological examination [25]. Instead, Ay et al. [6] proposed the most accurate classification system to date (CCS), based on evidence from a $2 \%$ stroke risk threshold, to differentiate an evident from a possible cause of stroke. However, the ideal application of CCS requires a full set of diagnostic investigations, which is currently not available in all stroke patients in all clinical settings.

Another issue is that of the cutoff we used to define LAD. We chose a TPA of $\geq 119 \mathrm{~mm}^{2}$ of plaque, which was the top quartile in our study in 2002 [11], that predicted a $19.5 \%$ 5-year risk of stroke, death or myocardial infarction, after adjusting for age, sex, blood pressure, smoking, cholesterol, diabetes, homocysteine and treatment of blood pressure and lipids. In 2004 we reported that TPA was a stronger predictor of risk than stenosis [26]. We acknowledge that this criterion might be different in other populations with different distributions of stroke risk factors and demographic characteristics. Indeed, a multicenter trial would provide the best source of evidence regarding the cutoff values of TPA to define high-risk LAD patients in multiple populations and clinical settings. A final limitation concerns the generalizability of this classification system.

Results from the Northern Manhattan Study [27], the Tromsø study $[28,29]$ and the High-Risk Plaque Study 
[30] show that plaque burden is currently measured in other clinical settings with similar results to those in our source population. It is expected that as the advantages of measuring plaque burden [31] become more widely appreciated, this will become the standard of care. As a result, we believe that there is a considerable potential for the use of SPARKLE in different clinical settings to provide the opportunity for early diagnosis and appropriate treatment of LAD.

Whether subtype classifications should be limited to patients with stroke or should include patients with TIA is an issue that some readers may question. In this study, 165 patients $(60 \%)$ had a stroke at baseline and 111 patients (40\%) had TIA (data included in online suppl. table 1). A number of studies used the TOAST system for subtype classification of patients with TIA, as well as a combined population of patients with TIA and minor stroke [7-9]. Furthermore, a recent study comparing TOAST, CCS and ASCO showed a similar distribution of ischemic stroke subtypes in patients with TIA compared to studies using only stroke patients [10]. The most appropriate and effective therapy to reduce the risk of recurrent stroke is the therapy that specifically targets the underlying cause; for example, a patient with giant cell arteritis needs high-dose corticosteroids, and patients with cardioembolic stroke need anticoagulants [32]. The greatest opportunity for prevention is in patients who have not yet had a devastating stroke; therefore subtype classification is particularly useful in patients with TIA or minor stroke. This is supported by the results of the EXPRESS study, where intensive and early medical treatment of patients with TIA/minor stroke resulted in an $80 \%$ reduction of the risk of recurrent stroke [33].

SPARKLE reflects current clinical practice and can be used in all clinical settings and in further epidemiological studies. However, confirmation of the reliability of this new classification system is required in multiple centers and from different raters. Moreover, a cluster-randomized clinical trial would provide the best evidence on the performance of SPARKLE compared to CCS by randomizing patients to clinical care with and without measurement of TPA. This could also be accompanied by genetic profile assessment to confirm which classification system can better identify patients of a particular stroke/TIA subtype. A clinical trial of this design could assess the prognostic value of each classification system.

\section{Conclusion}

Initial findings suggest that SPARKLE is a valid and reliable ischemic stroke classification system. Incorporating plaque burden into the definition of $\mathrm{LAD}$ reduces the proportion of cases classified as of undetermined etiology and thus permits more specific treatment of the underlying causes of cerebrovascular disease in order to reduce recurrent strokes.

\section{Acknowledgments}

We thank summer students at the SPARC - Karla Solo, Jacquie Filteau and Stephanie Lammers - who helped with data collection. Funding was provided by private donations to SPARC, and by the Government of Canada funding for summer students, through Western University.

\section{Disclosure Statement}

None of the authors has a conflict of interest in connection with the content of this paper.

\section{References}

$\checkmark 1$ Amarenco P, Bogousslavsky J, Caplan LR, Donnan GA, Hennerici MG: Classification of stroke subtypes. Cerebrovasc Dis 2009;27: 493-501.

-2 Mohr JP, Caplan LR, Melski JW, Goldstein RJ, Duncan GW, Kistler JP, Pessin MS, Bleich HL: The Harvard Cooperative Stroke Registry: a prospective registry. Neurology 1978;28: 754-762.

$>3$ Caplan LR: Stroke classification: a personal view. Stroke 2011;42:S3-S6.

$\checkmark 4$ Foulkes MA, Wolf PA, Price TR, Mohr JP, Hier DB: The Stroke Data Bank: design, methods, and baseline characteristics. Stroke 1988; 19:547-554.
5 Adams HP Jr, Bendixen BH, Kappelle LJ, Biller J, Love BB, Gordon DL, Marsh EE 3rd: Classification of subtype of acute ischemic stroke. Definitions for use in a multicenter clinical trial. TOAST. Trial of Org 10172 in Acute Stroke Treatment. Stroke 1993;24:35-41.

$\checkmark 6$ Ay H, Furie KL, Singhal A, Smith WS, Sorensen AG, Koroshetz WJ: An evidencebased causative classification system for acute ischemic stroke. Ann Neurol 2005;58:688697.

7 Clark JM, Renier SA: A community stroke study: factors influencing stroke awareness and hospital arrival time. J Stroke Cerebrovasc Dis 2001;10:274-278.
-8 Mlynash M, Olivot JM, Tong DC, Lansberg MG, Eyngorn I, Kemp S, Moseley ME, Albers GW: Yield of combined perfusion and diffusion MR imaging in hemispheric TIA. Neurology 2009;72:1127-1133.

9 Purroy F, Montaner J, Molina CA, Delgado P, Ribo M, Alvarez-Sabin J: Patterns and predictors of early risk of recurrence after transient ischemic attack with respect to etiologic subtypes. Stroke 2007;38:3225-3229.

-10 Amort M, Fluri F, Weisskopf F, Gensicke H, Bonati LH, Lyrer PA, Engelter ST: Etiological classifications of transient ischemic attacks: subtype classification by TOAST, CCS and ASCO - a pilot study. Cerebrovasc Dis 2012;33:508-516. 
-11 Spence JD, Eliasziw M, DiCicco M, Hackam DG, Galil R, Lohmann T: Carotid plaque area: a tool for targeting and evaluating vascular preventive therapy. Stroke 2002;33:29162922.

12 Iemolo F, Martiniuk A, Steinman DA, Spence JD: Sex differences in carotid plaque and stenosis. Stroke 2004;35:477-481.

13 Romanens M, Ackermann F, Spence JD, Darioli R, Rodondi N, Corti R, Noll G, Schwenkglenks M, Pencina M: Improvement of cardiovascular risk prediction: time to review current knowledge, debates, and fundamentals on how to assess test characteristics. Eur J Cardiovasc Prev Rehabil 2010;17:18-23.

$\checkmark 14$ Spence JD, Coates V, Li H, Tamayo A, Munoz C, Hackam DG, DiCicco M, DesRoches J, Bogiatzi C, Klein J, Madrenas J, Hegele RA: Effects of intensive medical therapy on microemboli and cardiovascular risk in asymptomatic carotid stenosis. Arch Neurol 2010;67: 180-186.

15 Spence JD, Hackam DG: Treating arteries instead of risk factors: a paradigm change in management of atherosclerosis. Stroke 2010 41:1193-1199.

16 Jackson C, Sudlow C: Are lacunar strokes really different? A systematic review of differences in risk factor profiles between lacunar and nonlacunar infarcts. Stroke 2005;36:891901.

17 McNemar Q: Note on the sampling error of the difference between correlated proportions or percentages. Psychometrika 1947;12:153157.

18 Cohen J: A coefficient of agreement for nominal scales. Educ Psychol Meas 1960;20:3746.

19 Landis JR, Koch GG: The measurement of observer agreement for categorical data. Biometrics 1977;33:159-174.

20 The R Project for Statistical Computing. www.r-project.org.

21 Palm F, Urbanek C, Wolf J, Buggle F, Kleemann T, Hennerici MG, Inselmann G, Hagar M, Safer A, Becher H, Grau AJ: Etiology, risk factors and sex differences in ischemic stroke in the Ludwigshafen Stroke Study, a population-based stroke registry. Cerebrovasc Dis 2012;33:69-75.
22 Jickling GC, Stamova B, Ander BP, Zhan X, Liu D, Sison SM, Verro P, Sharp FR: Prediction of cardioembolic, arterial, and lacunar causes of cryptogenic stroke by gene expression and infarct location. Stroke 2012;43: 2036-2041.

23 Fletcher RH, Fletcher SW: Clinical Epidemiology: The Essentials, ed 4. Philadelphia, Lippincott Williams \& Wilkins, 2005.

24 Arsava EM, Ballabio E, Benner T, Cole JW, Delgado-Martinez MP, Dichgans M, Fazekas F, Furie KL, Illoh K, Jood K, Kittner S, Lindgren AG, Majersik JJ, Macleod MJ, Meurer WJ, Montaner J, Olugbodi AA, Pasdar A, Redfors P, Schmidt R, Sharma P, Singhal AB, Sorensen AG, Sudlow C, Thijs V, Worrall BB, Rosand J, Ay H: The Causative Classification of Stroke system: an international reliability and optimization study. Neurology 2010;75: 1277-1284.

25 Ay H: Advances in the diagnosis of etiologic subtypes of ischemic stroke. Curr Neurol Neurosci Rep 2010;10:14-20.

26 Iemolo F, Martiniuk A, Steinman DA, Spence JD: Sex differences in carotid plaque and stenosis. Stroke 2004;35:477-481.

27 Kuo F, Gardener H, Dong C, Cabral D, DellaMorte D, Blanton SH, Elkind MS, Sacco RL, Rundek T: Traditional cardiovascular risk factors explain the minority of the variability in carotid plaque. Stroke 2012;43:1755-1760.

28 Johnsen SH, Mathiesen EB, Joakimsen O, Stensland E, Wilsgaard T, Lochen ML, Njolstad I, Arnesen E: Carotid atherosclerosis is a stronger predictor of myocardial infarction in women than in men: a 6-year follow-up study of 6,226 persons: the Tromsø Study. Stroke 2007;38:2873-2880.

29 Mathiesen EB, Johnsen SH, Wilsgaard T, Bonaa $\mathrm{KH}$, Lochen ML, Njolstad I: Carotid plaque area and intima-media thickness in prediction of first-ever ischemic stroke: a 10year follow-up of 6,584 men and women: the Tromsø Study. Stroke 2011;42:972-978.

30 Sillesen H, Muntendam P, Adourian A, Entrekin R, Garcia M, Falk E, Fuster V: Carotid plaque burden as a measure of subclinical atherosclerosis: comparison with other tests for subclinical arterial disease in the High-Risk Plaque BioImage Study. JACC Cardiovasc Imaging 2012;5:681-689.
1 Spence JD: Carotid plaque measurement is superior to IMT. Invited editorial comment on: Carotid plaque, compared with carotid intima-media thickness, more accurately predicts coronary artery disease events: a metaanalysis - Yoichi Inaba, MD, Jennifer A. Chen $\mathrm{MD}$, Steven R. Bergmann MD, PhD. Atherosclerosis 2011;220:34-35.

32 Spence JD, Barnett HJ: Stroke Prevention, Treatment and Rehabilitation. New York, McGraw-Hill, 2012.

33 Rothwell PM, Giles MF, Chandratheva A, Marquardt L, Geraghty O, Redgrave JN, Lovelock CE, Binney LE, Bull LM, Cuthbertson FC, Welch SJ, Bosch S, Alexander FC, Silver LE, Gutnikov SA, Mehta Z: Effect of urgent treatment of transient ischaemic attack and minor stroke on early recurrent stroke (EXPRESS study): a prospective populationbased sequential comparison. Lancet 2007; 370:1432-1442.

34 Arend WP, Armitage JO, Clemmons DR, Drazen JM, Griggs RC, LaRusso N: Cecil Medicine, ed 23. Philadelphia, Saunders Elsevier, 2008.

35 Osiro S, Zurada A, Gielecki J, Shoja MM, Tubbs RS, Loukas M: A review of subclavian steal syndrome with clinical correlation. Med Sci Monit 2012;18:RA57-RA63.

36 Bogiatzi C, Cocker MS, Beanlands R, Spence JD: Identifying high-risk asymptomatic carotid stenosis. Expert Opin Med Diagn 2012; 6:139-151.

37 Spence JD, Tamayo A, Lownie SP, Ng WP, Ferguson GG: Absence of microemboli on transcranial Doppler identifies low-risk patients with asymptomatic carotid stenosis. Stroke 2005;36:2373-2378.

38 Hauser S, Josephson S (eds): Harrison's Neurology in Clinical Medicine, ed 2. New York, McGraw-Hill Professional, 2010.

39 Gan R, Sacco RL, Kargman DE, Roberts JK, Boden-Albala B, Gu Q: Testing the validity of the lacunar hypothesis: the Northern Manhattan Stroke Study experience. Neurology 1997;48:1204-1211.

40 Glagov S, Weisenberg E, Zarins CK, Stankunavicius R, Kolettis GJ: Compensatory enlargement of human atherosclerotic coronary arteries. N Engl J Med 1987;316:1371-1375.
SPARKLE: A New Tool for the Classification of Ischemic Stroke Subtypes
Neuroepidemiology 2014;42:243-251 DOI: $10.1159 / 000362417$ 